\title{
FORMULATION AND EVALUATION OF TOPICAL NANOEMULGEL OF METHOTREXATE FOR RHEUMATOID ARTHRITIS
}

\author{
SAHELI DAS ${ }^{1}$, SHARADHA M. ${ }^{1}$, M. P. VENKATESH ${ }^{1}$, SUBHASHREE SAHOO ${ }^{1}$, JOGABRATA TRIPATHY ${ }^{1}$, D. V. \\ GOWDA $^{1^{*}}$
}

1,*Department of Pharmaceutics, JSS College of Pharmacy, JSS Academy of Higher Education and Research, Mysuru 570015, Karnataka, India Email: dvgowda@jssuni.edu.in

Received: 06 Feb 2021, Revised and Accepted: 22 Jun 2021

\section{ABSTRACT}

Objective: The purpose of this study was to develop and evaluate methotrexate-loaded nanoemulgel for topical delivery in the management of rheumatoid arthritis.

Methods: Based on nanoemulsion composition, the pseudo ternary phase diagram was fabricated by using peanut oil, Tween 20 as the surfactant, and PEG 400 being used as a co-surfactant. The methotrexate-loaded nanoemulsion was formulated by using the spontaneous emulsification method. Badam gum was used as a gel matrix in the prepared nanoemulsion to form nanoemulgel. The methotrexate-loaded nanoemulgel was characterized and evaluated for $\mathrm{pH}$, particle size, physical appearance, viscosity, spreadability, TEM, drug content, diffusion study, release kinetics, and stability studies.

Results: The nanoemulgel constituting 8.6\% peanut oil, 34.4\% of Tween 20 and PEG 400 as $\mathrm{S}_{\text {mix }}$ (surfactant and co-surfactant mixture), $43 \%$ water, and $12.5 \% \mathrm{w} / \mathrm{w}$ badam gum was concluded as optimized formulation. The prepared nanoemulgel was translucent in nature having a particle size of $195.1 \mathrm{~nm}$ and zeta potential of $-0.278 \mathrm{mV}$. Drug content and drug release for the optimized formulation were found to be $98.11 \pm 0.34 \%$ and $95.11 \pm 0.02 \%$ respectively. $\mathrm{pH}$, viscosity, and spreadability were found to be optimum. Stability study data showed that the prepared nanoemulgel was stable at different temperatures varying from -25 to $+45^{\circ} \mathrm{C}$.

Conclusion: Methotrexate-loaded nanoemulgel has been successfully formulated for topical drug delivery for the management of rheumatoid arthritis.

Keywords: Methotrexate, Nanoemulgel, Rheumatoid arthritis, Topical delivery, Peanut oil

(C) 2021 The Authors. Published by Innovare Academic Sciences Pvt Ltd. This is an open access article under the CC BY license (https://creativecommons.org/licenses/by/4.0/)

DOI: https://dx.doi.org/10.22159/ijap.2021v13i5.41026. Journal homepage: https://innovareacademics.in/journals/index.php/ijap

\section{INTRODUCTION}

Rheumatoid arthritis is one of the complex autoimmune disorders associated with chronic inflammatory pain, and swelling of joints, elbows, shoulders, ankles, and other organs of the body [1]. It is based on numerous interacting eco-physiological and genetic factors that make it difficult to learn its pathogenesis and to detect effective treatment. In rheumatoid arthritis disease, the immune system of the body affects its tissues along with joints[2]. In extreme cases, the disease also affects the internal organs of the body [3]. The linings of joints are affected by Rheumatoid arthritis, which causes painful swelling. The long-term inflammation that is related to rheumatoid arthritis may cause erosion of bone and joint deformity. The focal point in the treatment of rheumatoid arthritis is pain reduction, reduction of inflammation, and damage to joints [4-6].

There are different routes of drug administration for the treatment of rheumatoid arthritis such as enteral routes such as oral, buccal, sublingual, and parenteral routes such as intramuscular, intravascular, subcutaneous, and intra-articular, or topical route[4]. In the topical drug delivery system, the drug is introduced onto the surface of the body, by incorporating it into a formulation that can be absorbed. Topical delivery provides several benefits over oral delivery for the treatment of diseases together with allowing easy and continuous delivery of drugs and minimizing the increased drug plasma concentration (Cmax) [7, 9].

However, the drug quantity introduced by dermal application is pretty less because the delivery of drugs through the dermal application is seriously restricted by the incapacity of various drugs to pass through the skin at a therapeutic rate because of the presence of the external stratum corneum membrane barrier. It has been predicted that the system which use nanoparticles to deliver drug may offer a different possible approach for influencing the permeability of drug and it is also feasible that a topical delivery system by using nanoparticles might also cause a selection of their utilization in the treatment of rheumatoid arthritis $[8,9]$.
The topical delivery systems of drugs involve different types of dosage forms such as liquid, sprays, semisolid and solid powders. The semisolid dosage form, which is most extensively used for topical delivery systems involves creams, ointments, and gels. The gel is a network of cross-linked polymer that is swollen when comes in contact with liquid. The properties of gel rely mostly on the interaction that occurs between the polymer of solid-state and the component of the liquid medium. The formulation of topical gel offers a suitable delivery system for drugs as they cause a low level of greasiness and might be eliminated from the skin without any difficulty. In comparison to cream and ointments, the gel preparation offers higher stability and application properties [8].

Nanoemulsions are heterogeneous colloidal systems in the submicronic scale whereas colloidal particulate structure is taken into consideration as isotropous dispersions which are thermodynamically and kinetically stable that includes two incompatible components viz., water and oil, stabilized by an associate surface layer that includes an acceptable cosurfactant and surface active agent to create a single-stage [9]. The nanoemulsions have recently been categorized into three classes including oil-in-water kind (oil dispersed in water phase), (W/O) (aqueous phase is dispersed in oil phase), and bi-continuous type (microdomains of aqueous phase and oil phase are interconnected in the device). To stabilize these emulsions, both lipophilic and hydrophilic surface-active agents are concurrently used [10]. The nanoemulgel is a nanoemulsion-based hydrogel that is formed by adding nanoemulsion into a matrix of a hydrogel $[13,14]$. Nanoemulgel has various useful properties such as easily spreadable, easy to remove, less greasy, cause no staining, longer shelf life, thixotropic, aqueous soluble, bio-friendly, acceptable appearance, and translucent [15-17].

\section{MATERIALS AND METHODS}

\section{Materials}

Methotrexate was procured from Samarth Life Sciences Pvt. Ltd., Mumbai, India; Peanut oil was procured from fresh mill oil, local 
market; Tween 20 was purchased from Loba Chemie Pvt Ltd, Mumbai; Polyethylene Glycol 400 was purchased from Leonid Chemicals Pvt Ltd, Bangalore; Benzyl alcohol was purchased from Merck; Badam gum was prepared in the laboratory. Additional excipients and chemical reagents utilized were of laboratory and analytical grade.

\section{UV visible spectrophotometer}

A weighed amount of methotrexate nearly $100 \mathrm{mg}$ was dissolved in $100 \mathrm{ml}$ of phosphate buffer of $\mathrm{pH}(6.8)$ in a volumetric flask and filtered. Pipette out $1 \mathrm{ml}$ and make it up to $100 \mathrm{ml}$ with the phosphate buffer. Then the $\lambda_{\max }$ of methotrexate was estimated with the help of a UV visible spectrophotometer.

\section{Fourier transform infrared (FT-IR) analysis}

The drug-excipient compatibility of the pure drug and the physical mixture was determined using the FT-IR spectrophotometer (8400S, Shimadzu Kyoto, Japan). The pure drug methotrexate and the physical mixture were mixed separately with $\mathrm{KBr}$ in mortar and pestle and pressed in KBr press (Technosearch Instrument, Mumbai, India) at the pressure of 5 tons for $5 \mathrm{~min}$ to form $\mathrm{KBr}$ pellets or thin films and FT-IR spectra recorded in the wavelength range $4000-400 \mathrm{~cm}^{-1}[14]$.

\section{Selection of excipients}

The emulgel preparation for topical application should be non-irritant and least sensitive to the skin. To maintain the solubility of the drug in nanoemulsion, the drug must be soluble in the oil phase. The stability of nanoemulsion is maintained by using higher and lower HLB value of surfactant and co-surfactant were considered [15].

\section{Screening of oils, surfactants, and co-surfactants}

A primary examination of numerous oils, surface-active agents, and co-surfactants has been completed to check their lodging capacity toward methotrexate. The miscibility of Methotrexate in numerous oils, surface-active agents, and co-surfactants has been identified by adding an extra quantity of drug into $2 \mathrm{ml}$ of decided oil, surface active agent, and co-surfactant one after the other in a separate 10 $\mathrm{ml}$ volumetric flask via the use of a vortexing mixer. These volumetric flasks had been stored in an orbital shaker incubator (Remi, CIS24 BL, Mumbai, India) at $25 \pm 1.0^{\circ} \mathrm{C}$ for $72 \mathrm{~h}$ to attain a state of equilibrium. The samples which were equilibrated have been taken out from the shaker and centrifugation was done at 3000 RPM over 15 min by the use of centrifuge (Remi, India). Then, the supernatant formed has been taken and performed filtration of supernatant by using afilter paper. The methotrexate concentration has been identified in specific oil using UV-spectroscopy at $259 \mathrm{~nm}$ $[19,20]$.

\section{Construction of pseudo-ternary phase diagram}

The pseudo ternary phase diagrams had been constructed by using the method of aqueous titration to determine the region of nanoemulsion and to identify the size of the nanoemulsion region. For the construction of each pseudo-ternary phase diagram, the surfactant was mixed with co-surfactant $\left(\mathrm{S}_{\text {mix }}\right)$ in the ratio of $1: 1,1: 2$, 1:3, 3:1, and 2:1 (i.e., $\mathrm{Km}, \mathrm{w} / \mathrm{w}$ ). Then the part of each $S_{\text {mix }}$ has been combined with the oil in the ratio of $9: 1,8: 2,7: 3,6: 4,5: 5,4: 6,3: 7$, $2: 8$, and $1: 9(\mathrm{w} / \mathrm{w})$. By vortexing with vortexer for $5 \mathrm{~min}$, a transparent homogenous mixture of oil and the $S_{\text {mix }}$ component had been prepared [18]. Then titration of each mixture was carried out in drop by drop method with distilled water and prominently viewed for clarity of phase and ability to flow. The volume of water at which the transitions from transparency to turbidity occurred was supposed to be the titration's endpoint. From this titration method, the ratio of surfactant/co-surfactant $\left(S_{\text {mix }}\right)$ has been determined. These estimated values were utilized to identify the region of the nanoemulsion formulation with the selected amount of oil and surfactant and co-surfactant $\left(\mathrm{S}_{\mathrm{mix}}\right)$. Then the drug effect on the boundary of nanoemulsion that has been obtained from the pseudo ternary phase diagram was checked. The pseudo ternary phase diagram was constructed using the ProSim Ternary Diagram software [21,22].

\section{Preparation of methotrexate loaded nanoemulgel}

\section{Formulation of methotrexate nanoemulsion}

Methotrexate (1\%) was added to the mixture of tween 20, PEG 400, and peanut oil ratios (table 1) taken from the pseudo ternary phase diagram. The water was then added dropwise to the above solution and stirred at room temperature [21].

\section{Formulation of methotrexate nanoemulgel}

A measured amount of badam gum was added to distilled water and mixed it properly using a magnetic stirrer. The stirring was carried out uniformly and the gel was placed in the refrigerator for $24 \mathrm{~h}$. The formulation (F1-F3) was prepared using S3 nanoemulsion containing a $S_{\text {mix }}$ ratio of 3:1 given in table 2 [5].

Table 1: Composition of nanoemulsion with selected oil, surfactant, and co-surfactant

\begin{tabular}{|c|c|c|c|c|}
\hline \multirow{2}{*}{ Nanoemulsion code } & \multirow[t]{2}{*}{$\mathbf{S}_{\text {mix }} *$} & \multicolumn{3}{|c|}{ Excipients $(\% \mathrm{w} / \mathrm{w})$} \\
\hline & & Peanut oil & Tween20:PEG400 ( $\left.S_{\text {mix }}\right)$ & Water \\
\hline S1 & $1: 1$ & 15 & 45 & 40 \\
\hline S2 & $2: 1$ & 10 & 45 & 45 \\
\hline S3 & $3: 1$ & 10 & 40 & 50 \\
\hline
\end{tabular}

Note: $\mathrm{S}_{\text {mix }}$ represents the ratio of surfactant to cosurfactant.

Table 2: Composition of $0.5 \% \mathrm{w} / \mathrm{w}$ methotrexate-loaded nanoemulgel

\begin{tabular}{|c|c|c|c|c|}
\hline S. No. & Materials & F1* & F2* & F3* \\
\hline 1 & Methotrexate & 0.5 & 0.5 & 0.5 \\
\hline 2 & Peanut Oil & 12.9 & 8.6 & 8.6 \\
\hline 3 & Tween 20:PEG400 $\left(\mathrm{S}_{\text {mix }}\right)$ & 38.7 & 38.7 & 34.4 \\
\hline 5 & Water & 34.4 & 38.7 & 43 \\
\hline 6 & Badam Gum (1.5\%) & 12.5 & 12.5 & 12.5 \\
\hline 7 & Benzyl Alcohol & 1.5 & 1.5 & 1.5 \\
\hline
\end{tabular}

Note: F1, F2, and F3 represent the formulations of Methotrexate-loaded nanoemulgel.

\section{Evaluation of nanoemulgel}

\section{Transmission electron microscope}

The size and shape of nanoemulgel were examined by transmission electron microscope (TEM) (Philips CM 10, Philips electron optics, Eindhoven, The Netherlands) with the image software. The drug- loaded emulsion was spread on firmware-coated copper grids and absorbed after complete air drying [24, 25].

\section{Particle size analysis}

The particle size of the formulated nanoemulgel was measured using the dynamic light scattering method or photon correlation 
spectroscopy by using Zeta sizer (ZS 90, Malvern Instrument Ltd, UK). The prepared nanoemugel was diluted with deionized water (1:1000) and measured for the particle size [26, 27].

\section{Measurement of zeta potential}

Zeta potential for nanoemulgel was estimated using Zeta sizer (ZS 90, Malvern Instrument Inc, UK) by using an electrophoretic light scattering method. The formulated sample was placed in zeta cells and results were analyzed. The average of three measurements with Standard Deviation $( \pm S D)$ was reported $[26,28]$.

\section{Evaluation of nanoemulgel}

\section{Physical appearance of nanoemulgel}

The formulated nanoemulgel was examined visually for color, $\mathrm{pH}$, homogeneity, stability, and consistency [27]

\section{Determination of $\mathbf{p H}$}

The $\mathrm{pH}$ of the formulated nanoemulgel was identified by utilizing a digital $\mathrm{pH}$ meter. By using distilled water the electrode of the $\mathrm{pH}$ meter has been washed and then the electrode was dipped inside the formulation to estimate $\mathrm{pH}$ [28].

\section{Viscosity measurement}

The viscosity of nanoemulgel was measured by Brookfield Viscometer (Brook field DV II+, USA), with spindle no. 63 at 30-50 RPM [25].

\section{Spreadability study}

Spreadability was estimated by calculating the diameter of the spreading of $1 \mathrm{~g}$ of formulation between two glass plates and for one minute when a standard weight of $20 \mathrm{~g}$ was employed to the upper plate.

$$
\mathrm{S}=\frac{m \times l}{t}
$$

where, $\mathrm{S}=$ spreadability $(\mathrm{cm} . \mathrm{g} / \mathrm{sec}), \mathrm{M}=$ weight of the upper slide (g), L=length of the glass slide $(\mathrm{cm})$ and $\mathrm{T}=$ time taken for separation of slide (sec) [29].

\section{Drug content study}

The study of drug content has been performed to estimate the presence of the drug in a certain amount of the prepared formulation. $0.1 \mathrm{~g}$ of the nanoemulgel has been weighed accurately and dissolved in $25 \mathrm{ml}$ of phosphate buffer ( $\mathrm{pH}$ 6.8). Then the volumetric flask was placed in an orbital shaker and shaken well to mix it properly. The solution was then filtered, suitably diluted and the absorbance was determined by UV-spectrophotometer at $259 \mathrm{~nm}$ [16].

\section{Drug release studies}

The release rate of methotrexate from nanoemulgel was performed using Franz diffusion cell (Perme Gear, Bethlehem, PA, USA), with a dialysis membrane of $0.65 \mu \mathrm{m}$ pore size. The diffusion test apparatus was performed using $900 \mathrm{ml}$ of phosphate buffer of $\mathrm{pH} 6.8$ at $37^{\circ} \mathrm{C} \pm 1^{\circ} \mathrm{C}$ and $50 \mathrm{RPM}$ for $12 \mathrm{~h}$. The methotrexate-loaded nanoemulgel was employed on the surface of the membrane in the donor chamber. Then the sample $(5 \mathrm{ml})$ was collected at a suitable interval of time (1, $2,3,6,9$, and $12 \mathrm{hr}$ ) from the receptor chamber, and to maintain the sink condition the receptor chamber was restored with buffer media. Then the collected samples were assayed for the measurement of drug content by utilizing a UV-visible spectrophotometer (UV-1800, Shimadzu, Kyoto, Japan) at $\lambda_{\max }$ of $259 \mathrm{~nm}$ [30].

\section{Release kinetics}

The cumulative drug release data was used to obtain mathematical models (Zero-order release, First-order release, Higuchi, and Korsmeyer-Peppas model) using BCP software [27].

\section{Accelerated stability studies}

The stability of the prepared nanoemulgel formulation was estimated using the heating-cooling cycle method and free thaw cycle method [31].

\section{Heating cooling cycle method}

In this method, 6 cycles were carried out between the refrigerator temperature $\left(4^{\circ} \mathrm{C}\right.$ and $\left.45^{\circ} \mathrm{C}\right)$ with the storage of the sample at each temperature for at least $48 \mathrm{~h}$ [16].

\section{Free thaw cycle}

In this method, the prepared nanoemulgel was initially placed in a deep freezer at a temperature of $-25^{\circ} \mathrm{C}$, then formulation was removed and allowed for thawing at a temperature of $25^{\circ} \mathrm{C}$ (room temperature). The formulation was then observed for appearance, $\mathrm{pH}$, and a viscosity [23].

\section{RESULTS AND DISCUSSION}

\section{Pre-formulation studies}

The absorption maxima of methotrexate were estimated at $259 \mathrm{~nm}$ in phosphate buffer of $\mathrm{pH} 6.8$.

\section{Fourier transform infrared spectroscopy (FT-IR)}

The FT-IR spectrum of pure methotrexate was compared with the FT-IR spectra of drug and excipients as shown in fig. 1. The functional group along with their wavenumbers obtained for both the pure drug and the physical mixture has been listed in table 3 . The characteristic IR peaks of pure Methotrexate were found to be at 1446.66 ( $\mathrm{C}-\mathrm{H}$ bending, deformation of $\left.\mathrm{CH}_{3}\right), 1637.48$ ( $\mathrm{C}=\mathrm{C}$ stretching), 2928.04 (C-H stretching, aliphatic), 3371.63 (O-H stretching) [32]. All these peaks were found to be in the IR spectra of the physical mixture with not so much major shifting. Therefore, both pure drug and the physical mixture were in correlation with all the characteristic IR spectra peaks and the results revealed no chemical interaction between drug and excipients.

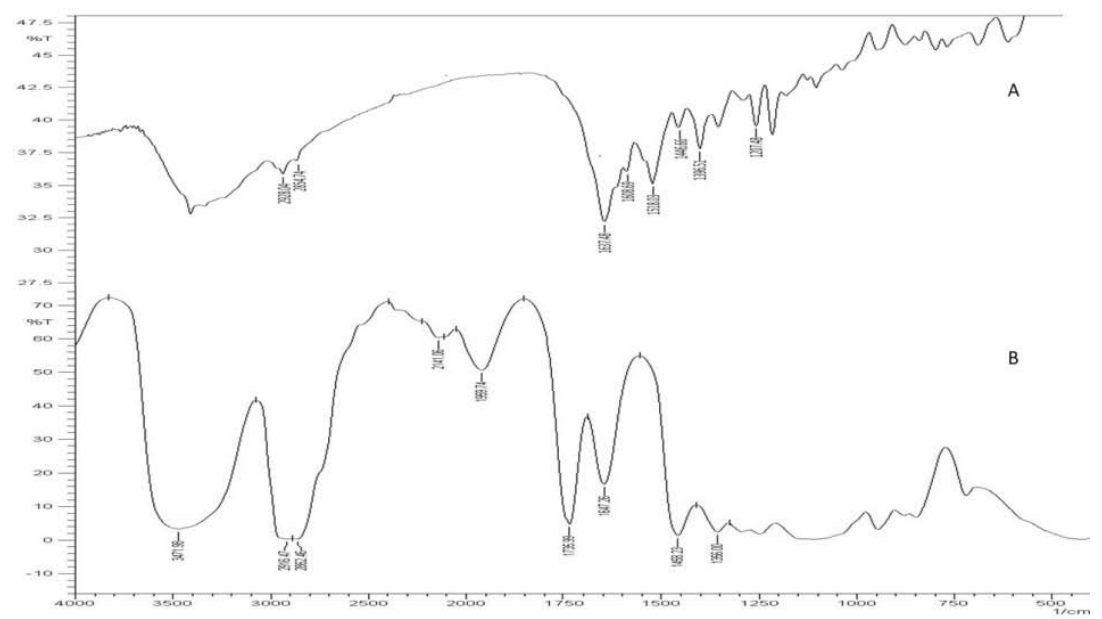

Fig. 1: FT-IR spectra of (A) methotrexate and (B) Physical mixture (Methotrexate+Peanutoil+Tween 20+PEG 400) 
Table 3: FTIR spectrum of the pure drug (methotrexate) and the physical mixture

\begin{tabular}{lll}
\hline Functional group & Pure drug & Physical mixture \\
\hline C=Cstretch & 1637.48 & 1647.26 \\
C-H bend (deformation of $\mathrm{CH}_{3}$ ) & 1446.66 & 1458.23 \\
C-H stretch (Aliphatic) & 2928.04 & 2916.47 \\
O-H stretch & 3371.63 & 3471.98 \\
\hline
\end{tabular}

\section{Pseudo-ternary diagram}

From the pseudo-ternary-phase diagram, it has been observed that there is a slight alteration in the nanoemulsion region with the increase in the surfactant ratio. Hence, according to the pseudo-phase ternary diagram, the $S 3$ formulation, a 3:1 ratio of $S_{\text {mix }}$ (Tween 20:PEG $400)$ was considered. The 1:9 ratio of oil: $S_{\text {mix }}$ has been considered as the maximum region of nanoemulsion as depicted in fig. 2 .

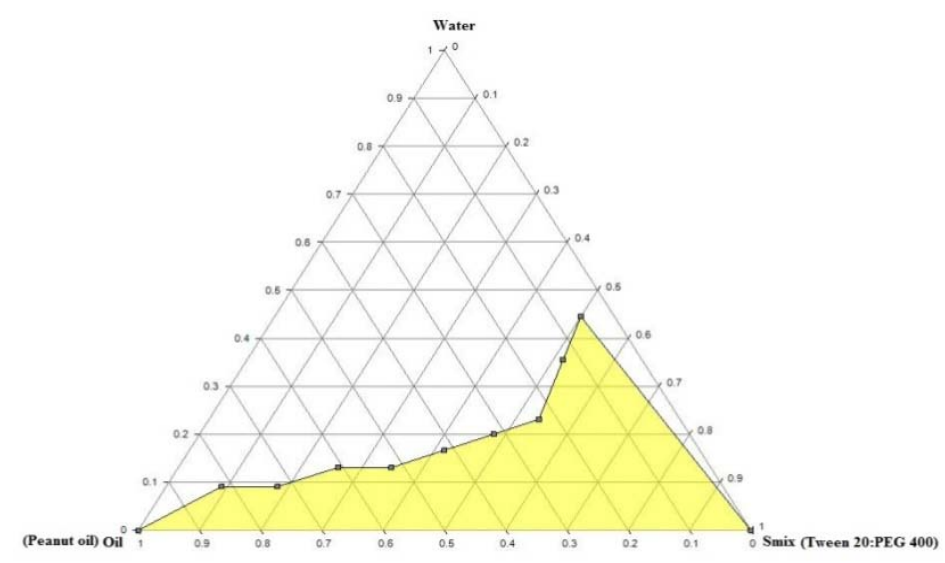

Fig. 2: Pseudo-ternary phase diagram of methotrexate

\section{Evaluation of nanoemulsion}

\section{Transmission electron microscope (TEM)}

TEM was implied for evaluating particle shape and size of nanoemulgel. The TEM results of optimized formulation F3 revealed that the particle size of methotrexate-loaded nanoemulgel was found to be $195.1 \mathrm{~nm}$, the same when compared with the particle analyzer (fig. 3b), with the uniform shape of particles. The TEM images of nanoemulgel are depicted in fig. 3a.

\section{Particle size analysis}

The particle size of the formulation was found to be $195.1 \mathrm{~nm}$ and the polydispersity index (PDI) was found to be 0.326 as shown in fig. $3 \mathrm{~b}$. As per the thumb rule, the PDI value was found to be monodisperse and ensures stability.

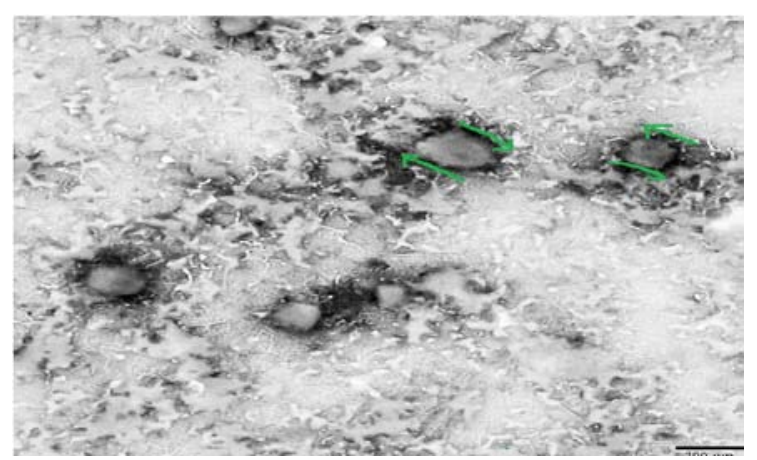

Fig. 3a: TEM image of methotrexate loaded nanoemulgel

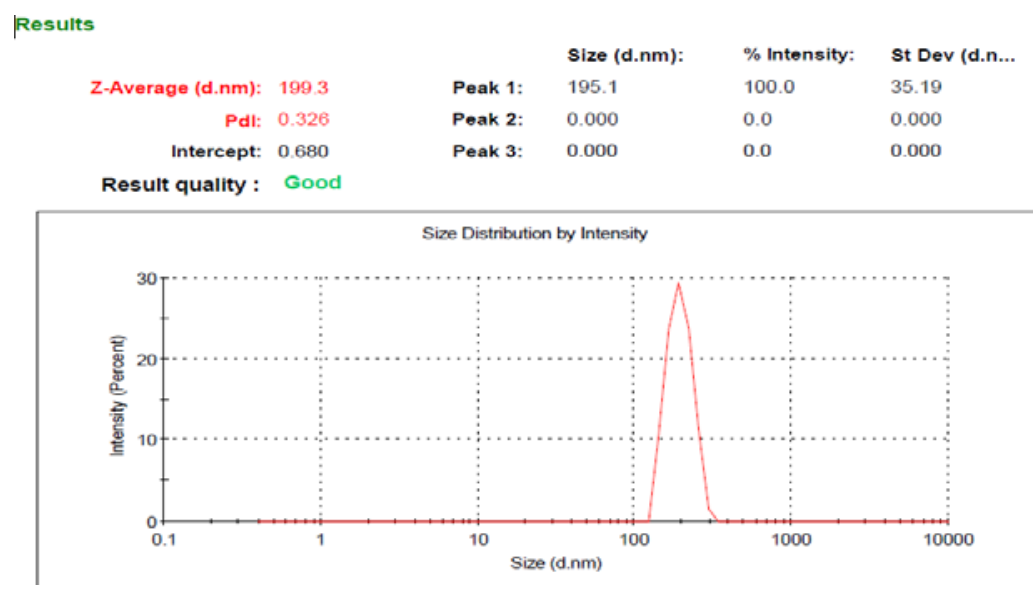

Fig. 3b: Particle size of methotrexate loaded nanoemulgel 


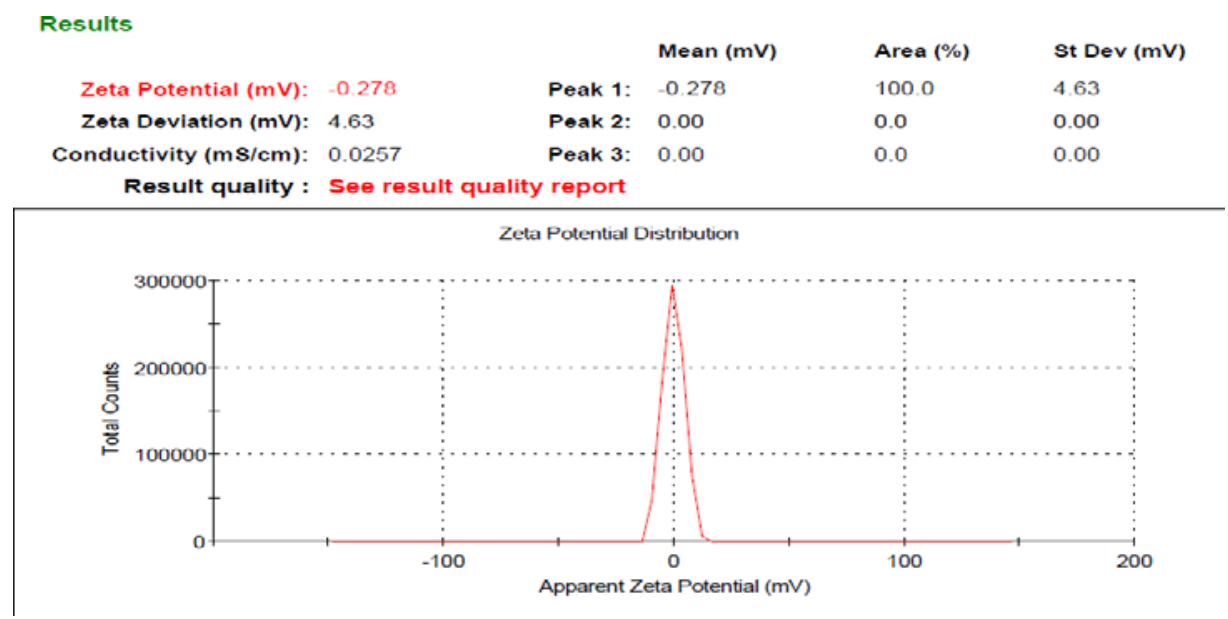

Fig. 4: Zeta potential of methotrexate loaded nanoemulgel

\section{Measurement of zeta potential}

The zeta potential of the prepared formulation was $-0.278 \mathrm{mV}$, which was within the limit, and indicates thermodynamic stability as shown in fig. 4.

\section{Evaluation of nanoemulgel}

\section{Physical appearance of nanoemulgel}

The nanoemulgel prepared using badam gum was yellowish, translucent, and consistent in appearance.

\section{Determination of $\mathrm{pH}$}

The $\mathrm{pH}$ of these formulations was ranged between 5.8 and 6.7. Which are considered acceptable and less irritable for use in human skin, as human skin pH is 5.5. Therefore, it is feasible to apply on the skin with no irritation.

\section{Viscosity measurement}

The viscosity of nanoemulgel was found to be $1533.1 \mathrm{cps}$ at $50 \mathrm{rpm}$, implying the better consistency of the dosage form.

\section{Spreadability study}

The spreadability of nanoemulgel was found to be $28.85 \mathrm{~g} \mathrm{~cm} / \mathrm{sec}$. Hence, the range was acceptable.

\section{Drug content study}

The drug content of a nanoemulgel was $98.11 \pm 0.34 \%$, implying that a significant amount of the drug was loaded in the nanoemulgel.

\section{Drug release study}

In vitro drug release of the optimized formula was performed in PBS of $\mathrm{pH} 6.8$ by using a dialysis membrane. The $\mathrm{F} 3$ formulation showed burst release initially as compared to the other formulations. The drug release of optimized drug-loaded nanoemulgel (F3) was found to be $95.11 \%$ in $12 \mathrm{~h}$ when compared to other formulations and is depicted in table 4 and fig. 5.

\section{Release kinetics}

The optimized drug-loaded nanoemulgel (F3) showed the highest percentage of drug release of $95.11 \%$ when compared to the other formulations and followed first-order kinetics. Therefore, the release profile that followed the diffusion process is the First Order model with an $\mathrm{R}^{2}$ value of 0.9915 and also achieved a linear relationship as given in table 5.

\section{Accelerated stability studies}

Under all storage conditions, the optimized formula has been kept and the physical characteristics have been evaluated. From the stability study, it has been found that the prepared nanoemulgel was physically stable at all storage conditions with no phase separation, caking, and creaming. Hence, the optimized formula is kinetically stable.

Table 4: Data for in vitro drug diffusion studies

\begin{tabular}{llll}
\hline Time in hours & \multicolumn{2}{l}{ \% Drug diffused $(\mathbf{w} / \mathbf{w})$ Mean \pm SD } & F3 \\
\cline { 2 - 4 } & F1 & F2 & 0.00 \\
\hline 0 & 0.00 & 0.00 & $7.02 \pm 0.05$ \\
1 & $4.09 \pm 0.03$ & $5.12 \pm 0.02$ & $16.92 \pm 0.03$ \\
2 & $15.06 \pm 0.04$ & $15.88 \pm 0.03$ & $26.63 \pm 0.05$ \\
3 & $22.55 \pm 0.05$ & $23.78 \pm 0.02$ & $44.72 \pm 0.02$ \\
6 & $40.98 \pm 0.02$ & $42.01 \pm 0.01$ & $61.26 \pm 0.01$ \\
9 & $59.12 \pm 0.03$ & $58.67 \pm 0.04$ & $95.11 \pm 0.02$ \\
12 & $80.24 \pm 0.01$ & $85.19 \pm 0.002$ & \\
\hline
\end{tabular}

NOTE: $*$ Data represented as mean \pm SD $(n=3)$

Table 5: Release kinetics at $259 \mathrm{~nm}$

\begin{tabular}{ll}
\hline Mathematical model & $\mathbf{R}^{2}$ of nanoemulgel (F3) \\
\hline Zero Order Release & 0.9894 \\
First Order Release & 0.9915 \\
Higuchi Model & 0.9168 \\
Korsmeyer Peppas Model & 0.9881 \\
\hline
\end{tabular}

NOTE: $\mathrm{R}^{2}=$ Regression coefficient value 


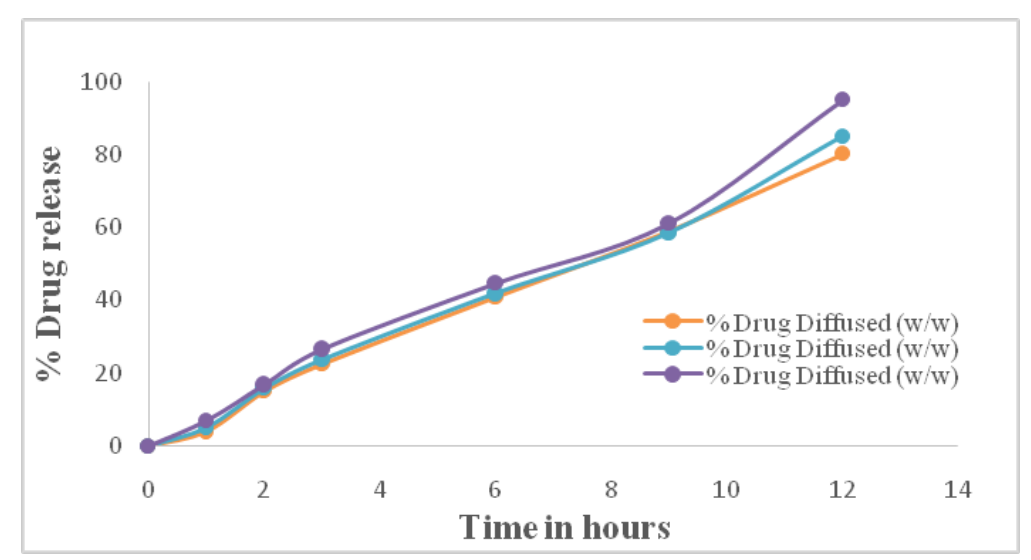

Fig. 5: Graph showing percentage drug diffused of methotrexate and nanoemulgel at $259 \mathrm{~nm}$

\section{CONCLUSION}

Topical drug delivery is the preferred route for the local application of the therapeutic drug because of its ease and affordability. It has also gained popularity in recent years among the population due to better patient compliance. Therefore, a potential methotrexateloadednanoemulgel using peanut oil as the oil phase and badam gum as a gelling agent was formulated successfully and characterized along with an in vitro study. The optimized formulation (F3) showed $95.11 \%$ in $12 \mathrm{~h}$ which is more than the other formulation and also resulted in better physicochemical properties. The product exhibit a good stability profile at all storage condition mentioned in the methodology. So, from this research study, it has been found that methotrexate is a disease-modifying antirheumatic drug with a better retention time as compared to other drugs. Hence, the study demonstrated that the prepared nanoemulgel was found to be an operative tool in the management of rheumatoid arthritis when applied topically with a longer stability profile.

\section{FUNDING}

Nil

\section{AUTHORS CONTRIBUTIONS}

All authors have contributed equally.

\section{CONFLICTS OF INTERESTS}

The author has no conflict of interest to declare.

\section{REFERENCES}

1. Sohel S, Najmuddin M, Hariprasanna RC, Kishore VC Development and evaluation of orally disintegrating tablet of celecoxib for juvenile rheumatoid arthritis. Res J Pharm Technol 2013;6:865-7.

2. Srivastava S, Patel S, Daharwal SJ, Singh D, Singh M. Rheumatoid arthritis: an autoimmune disease prevalent in females. Res J Pharm Technol 2016;9:170-2.

3. Kumar SS, Bhosle D, Janghel A, Deo S, Raut P, Verma C, et al. Indian medicinal plants used for the treatment of rheumatoid arthritis. Res J Pharm Technol 2015;8:597-610.

4. Das AP, Bhattacharjee S. Rheumatoid arthritis: molecular basis and cures from nature. Int J Pharm Pharm Sci 2015;7:30-9.

5. Gadkari PN, Patil PB, Saudagar RB. Formulation, development and evaluation of topical nanoemulgel of tolnaftate. J Drug Delivery Ther 2019;9:208-13.

6. Choudhury H, Gorain B, Pandey M, Chatterjee LA, Sengupta P, Das A, et al. Recent update on nanoemulgel as topical drug delivery system. J Pharm Sci Elsevier Inc 2017;106:1736-51.

7. Cutolo M, Sulli A, Pizzorni C, Seriolo B, STRAUB RH. Antiinflammatory mechanisms of methotrexate in rheumatoid arthritis. Ann Rheum Dis 2001;60:729-35.

8. Kaur J, Kaur J, Jaiswal S, Gupta G. Recent advances in topical drug delivery system. Pharm Res 2016;6:1.
9. Uma SK, Alagusundaram M, Sahithi GK, Chetty CMS, Ramkanth $\mathrm{S}$, Angalaparameswari $\mathrm{S}$, et al. Nanoemulsions-approaching thermodynamic stability. Res J Pharm Technol 2010;3:319-26.

10. Mahdi ZH, Maraie NK. Overview on nanoemulsion as a recently developed approach. Drug Nanoformulation 2019;12:5554-60.

11. Raut S, Uplanchiwar V, Bhadoria S, Gahane A, Jain SK, Patil S. Comparative evaluation of zidovudine loaded hydrogels and emulgels. Int J Pharm Technol 2012;5:41-5.

12. Sravan VN, Varma K, Maheshwari PV, Navya M, Reddy SC, Shivakumar HG, et al. Calcipotriol delivery into the skin as emulgel for effective permeation. SAUDI Pharm J. King Saud University; 2014.

13. Sengupta P, Chatterjee B. Potential and future scope of nanoemulgel formulation for topical delivery of lipophilic drugs. Int J Pharm 2017;526:353-65.

14. Shaji J, Shinde A. Formulation and evaluation of floating pulsatile microspheres of aceclofenac for rheumatoid arthritis. Res J Pharm Technol 2011;4:1877-81.

15. Kapoor K, Pandit V, Nagaich U. Development and characterization of sustained-release methotrexate loaded cubosomes for topical delivery in rheumatoid arthritis. Int J Appl Pharm 2020;12:33-9.

16. Acharya U, Rajarajan S, Acharya R, Acharya R, Ghimire S. Formulation and evaluation of nano emulsion based system for transdermal delivery of antipsoriatic. World J Pharm Pharm Sci 2017;6:732-48.

17. Kumar B, Jain SK, Prajapati SK, Mahor A, Kumar A. Development and characterization of transdermal microemulsion gel for an antiviral drug. IJPSR 2010;1:57-74.

18. Article 0 . Study of enhanced anti-inflammatory potential of nigella sativa in topical. Int J Pharm Pharm Sci 2018;10:41.

19. Shafiq-un-nabi S, Shakeel F, Talegaonkar S, Ali J, Baboota S, Ahuja A, et al. Formulation development and optimization using nanoemulsion technique. Technical Note 2007;8:1-6.

20. Shakeel F, Ramadan W. Transdermal delivery of anticancer drug caffeine from water-in-oil nanoemulsions. Colloids Surf B 2010;75:356-62.

21. Mishra VVBK, Bhanja SB, Panigrahi BB. Development and evaluation of nanoemulsion gel for transdermal delivery of valdecoxib. Int J Pharm Technol 2019;12:600-10.

22. Lathiyare KB, Jain V. Development and characterization of karanj oil-based proniosomal gel for topical delivery. Res J Pharm Technol 2014;7:952-62.

23. Talegaonkar S, Mustafa G, Akhter S, Iqbal ZI. Design and development of oral oil-in-water nanoemulsion formulation bearing atorvastatin: in vitro assessment. J Dispers Sci Technol 2010;31:690-701.

24. Zhou H, Yue Y, Liu G, Li Y, Zhang J, Gong Q, et al. Preparation and characterization of a lecithin nanoemulsion as a topical delivery system. Nanoscale Res Lett 2010;5:224-30.

25. Khunt DM, Mishra AD, Shah DR. Formulation design and development of piroxicam emulgel. Int J PharmTech Res 2012;4:1332-44. 
26. Prasetyo BE, Karsono, Maruhawa SM, Laila L. Formulation and physical evaluation of castor oil based nanoemulsion for diclofenac sodium delivery system. Res J Pharm Technol 2018;11:3861-5.

27. Mengesha M. Preparation, characterization and optimization of oromucosal clotrimazole emulgel formulation; 2015;6. Available from: http://localhost:80/xmlui/handle/ 123456789/1017 [Last accessed on 10 Mar 2015]

28. Bhattacharya S, Prajapati BG. Formulation and optimization of celecoxib nanoemulgel. Asian J Pharm Clin Res 2017; 10:353-65.
29. Pouton CW. Formulation of self-emulsifying drug delivery systems. Adv Drug Delivery Rev 1997;25:47-58.

30. Verma S, Singh AK, Mukerjee A. Formulation and evaluation of ketoconazole. World J Pharm Pharm Sci 2016;5:899-911.

31. Mishra VVBK, Bhanja SB, Panigrahi BB. Development and evaluation of nanoemulsion gel for transdermal delivery of valdecoxib. Res J Pharm Technol 2019;12:600-10.

32. Chakraborty M, Dasgupta S, Bose P, Misra A, Kumar Mandal T, Mitra $\mathrm{M}$, et al. Layered double hydroxide: inorganic-organic conjugate nanocarrier for methotrexate. J Phys Chem Solids 2011;72:779-83. 